\section{Enucleation assisted with filler for open-globe injury}

\author{
Ayako Takahashi, ${ }^{1}$ Masayuki Akimoto, ${ }^{1,4}$ \\ Sachiyo Hama, ${ }^{1}$ Yoko Shirai, ${ }^{2}$ \\ Sachiko Minamiguchi ${ }^{3}$ \\ Departments of ${ }^{1}$ Ophthalmology, \\ ${ }^{2}$ Dentistry, ${ }^{3}$ Pathology, ${ }^{4}$ Clinical Research \\ Institute, Kyoto Medical Center, National \\ Hospital Organization, Kyoto Medical \\ Center, Japan
}

\section{Abstract}

In cases of severe open-globe injury, it is often difficult to reconstruct the globe and maintain visual acuity. Ocular globe enucleation may decrease the risk of sympathetic ophthalmia in the fellow eye. However, the surgical procedure is difficult to perform with an open globe, because the injured globe is inclined to collapse. We report the case of an enucleation for an open-globe injury in which we used alginate, which is often used for dental impressions, as filler for the collapsed globe. We were able to maintain the resistance of the globe sufficiently well enough to perform the procedure easily and without complication. Thus, alginate may be a novel aid to assist in enucleation by preserving globe resistance.

\section{Introduction}

Ocular globe enucleation is often a necessary procedure following open-globe injury when the eye is diagnosed as being incapable of reconstruction. However, enucleation is often difficult to perform in open globe injuries, because the injured globe is inclined to collapse, despite filling it up with air or liquid. Here, we report a case in which enucleation was performed easily and without complication, using alginate as the filler. Alginate is often used for dental impressions because it is a soft gel that rapidly turns into a solid.

\section{Case Report}

A 74-year-old man who was hit by a car and suffered an open globe injury deemed incapable of being reconstructed. His left eye was perforated at the upper temporal corneal limbus, from the $110^{\prime}$ clock to the $50^{\prime}$ clock position, and totally collapsed (Figure 1A). In order to prevent sympathetic ophthalmia (SO) of the right eye, enucleation was deemed inevitable.
A decision was made to enucleate the left eye, on the tenth day after the injury. Informed consent was obtained; the operation was performed in conformity with the Declaration of Helsinki and was approved by our ethical committee.

The operation was performed under general anesthesia. Following standard sterile technique, the conjunctiva was incised at the fornix base and the sclera was exposed. The scleral wound was closed using interrupted 8-0 silk suture. Physiologic saline was injected into the globe through the wound. An attempt was made to aspirate the content of the globe; however, only little amount was aspirated.

Then, alginate was prepared, just before its use, because it begins to harden within 1 minute. A spoonful ( $8.4 \mathrm{~g}$ ) of alginate powder (Aroma Fine Plus ${ }^{\circledR}$ Normal Set, GC International Corp., Tokyo, Japan), sterilized by ethylene oxide gas and $20 \mathrm{~mL}$ of cold water were vigorously mixed together with a spatula and poured into a $10 \mathrm{~mL}$ syringe; cooler water allows for a longer working time. Two 18 gauge needles were inserted into the globe through the corneal limbus. Carbon dioxide gas was injected by insufflator (Alpha DuoLap, GIMMI, Tuttlingen, Germany) through one of the needles to inflate the collapsed globe, and then alginate was injected, up to approximately 3 $\mathrm{mL}$ through the second needle until the globe had sufficiently recovered its resistance. Excessive alginate that leaked out of the globe was easily removed after it had solidified.

The globe was subluxated by tenotomy of the 4 recti and 2 oblique muscles, and the optic nerve was cut. These procedures were much easier following injection of the alginate, because of the adequate resistance of the globe. The globe was completely enucleated without any further damage (Figures 1B-D).

\section{Discussion}

Open-globe injury can induce SO in the fellow eye, which is believed to be an autoimmune inflammatory response. The incidence of S0 after open-globe injury has been reported to be $0.1-0.3 \%{ }^{1-4}$ The time for SO to develop varies from 2 weeks to 50 years, with approximately $90 \%$ of patients developing the disease within 1 year of injury. ${ }^{5} \mathrm{SO}$ is in itself a sightthreatening disease. Definitive prevention of S0 requires prompt (within 2 weeks following the injury) enucleation or evisceration of the injured eye, especially when there is little possibility for the injured eye to regain any function. ${ }^{5}$ Enucleation is also performed for other reasons such as painful or disfiguring blind eye, neoplasm, and infection. ${ }^{6}$

In cases where the globe is collapsed, often following open-globe injury, enucleation may
Correspondence: Masayuki Akimoto, Department of Ophthalmology, National Hospital Organization, Kyoto Medical Center, 1-1 Fukakusa-Mukaihatacho, Fushimiku, Kyoto 6128555, Japan.

Tel: +81.75 .641 .9161 - Fax: $+81.75-643.4325$.

E-mail: masayuki@akimoto3.com

Key words: trauma, enucleation, filler, sympathetic ophthalmia.

Contributions: AT, MA, SH original idea and discussions; AT, MA, surgical procedure; AT, manuscript writing; YS, assisting in the use of the alginate; SM, specimen sectioning and imaging.

Conflict of interest: the authors report no conflicts of interest.

Received for publication: 27 April 2011.

Accepted for publication: 3 June 2011.

This work is licensed under a Creative Commons Attribution NonCommercial 3.0 License (CC BYNC 3.0).

(C) Copyright A. Takahashi et al., 2011

Licensee PAGEPress, Italy

Eye Reports 2011; 1:e2

doi:10.4081/eye.2011.e2

be a technically difficult procedure. Acquiring sufficient resistance of the globe can make enucleation easier and decrease the risk of trauma to the remaining orbital structures. Several innovative methods for enucleation have been reported. Torres et al. invented a new device which consists of surgical scissors custom made to have two connectable arms adapted to modified spoons and blades. ${ }^{7}$ Finger et al. used an original cryotherapy probe to induce proptosis during optic nerve transection. ${ }^{8}$ However, these ideas do not address the issue of the collapsed globe.

Alginate is an anionic polysaccharide distributed widely in the cell walls of brown algae. By binding with water, it forms a viscous gum, which is universally used for dental impressions. Alginate is also used in a variety of other applications, including the treatment of peptic ulcers and gastroesophageal reflux disease and as a substance for endoscopic hemostasis. Further, calcium alginate is used in dressings for traumatic wounds in order to promote healing and prevent infection. Tane et al. reported that calcium alginate sheets were effective for use in wound dressing in a case after ocular evisceration. ${ }^{10}$ Alginate is also used in biologic experiments for the immobilization of cells. This wide use of alginate suggests its physiologic safety. In a manner similar to dental application, ophthalmologists use alginate for the fabrication of ocular prostheses before and after enucleation. ${ }^{11}$

Tanaka et al. demonstrated that alginate 

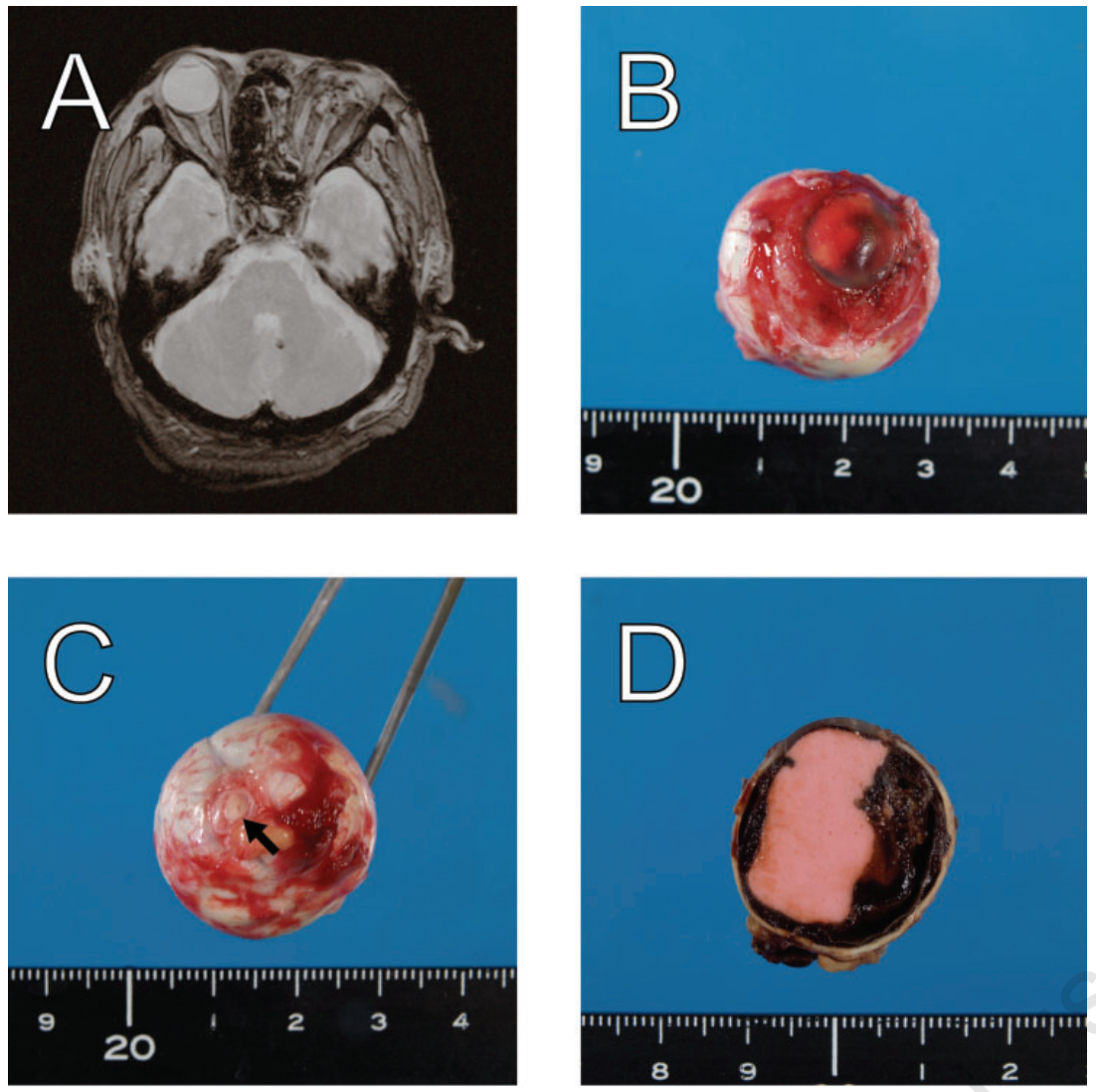

Figure 1. (A) T2-weighted magnetic resonance image before enucleation, demonstrating that the patient's left globe had totally collapsed; (B) Injected alginate preserved the resistance of the globe, which assisted with enucleation; (C) Good transection of the optic nerve was observed, suggesting that enucleation was performed completely without unnecessary trauma. Arrow indicates the stump of the optic nerve; (D) Alginate was evenly distributed in the cavity of the globe.

impression materials were sterilized by ethylene oxide gas and useful as filler for removing mucous retention cysts. ${ }^{12}$ This report encouraged us to use alginate as filler for the open globe during enucleation to preserve the resistance of the globe, which may be applicable even if the globe is ruptured. Alginate is inexpensive and easily commercially available. Its preparation for use as filler and its injection do not require any special technique. Thus, except in cases in which a pathologic diagnosis of the enucleated tissue is necessary, alginate may be a novel aid to assist in enucleation by preserving the resistance of the globe.

\section{References}

1. Kilmartin DJ, Dick AD, Forrester JV.
Prospective surveillance of sympathetic ophthalmia in the UK and Republic of Ireland. Br J Ophthalmol 2000;84:259-63.

2. Zhang Y, Zhang MN, Jiang $\mathrm{CH}$, Yao Y. Development of sympathetic ophthalmia following globe injury. Chin Med J (Engl) 2009;122:2961-6.

3. Savar A, Andreoli MT, Kloek CE, Andreoli CM. Enucleation for open globe injury. Am J Ophthalmol 2009;147:595-600.el.

4. Mansouri M, Faghihi H, Hajizadeh F, et al. Epidemiology of open-globe injuries in Iran: analysis of 2,340 cases in 5 years (report no. 1). Retina 2009;29:1141-9.

5. Sen HN, Nussenblatt RB. Sympathetic ophthalmia: what have we learned? Am J Ophthalmol 2009;148:632-3.

6. Rasmussen ML, Prause JU, Johnson M, Kamper-Jørgensen F, Toft PB. Review of 345 eye amputations carried out in the period 1996-2003, at Rigshospitalet, Denmark. Acta Ophthalmol 2010;88:21821.

7. Torres VL, Schor P, Erwenne CM. A new device for ocular globe enucleation. Ophthalmic Surg Lasers Imaging 2008;39:524-7.

8. Finger PT. "Finger-tip" cryoprobe assisted enucleation. Am J Ophthalmol 2005;139: 559-61.

9. Tytgat GN, McColl K, Tack J, et al. New algorithm for the treatment of gastrooesophageal reflux disease. Aliment Pharmacol Ther 2008;27:249-56.

10. Tane N, Ohira A, Aihara M. Use of calcium alginate for the eye socket wound dressing. Jpn J Clin Ophthalmol 2009;63:1175-9.

11. Mathews MF, Smith RM, Sutton AJ, Hudson R. The ocular impression: A review of the literature and presentation of an alternate technique. J Prosthodont 2000;9:210-6.

12. Tanaka Y, Harada T, Naito S, Yoshimura Y. Usefulness of Therapeutic Method for Mucous Retention Cysts of Oral Floor using Alginate Impression Material. J Jpn Stomatol Soc 1999;48:134-7. 